\title{
Safety and Efficacy of Long-Term Ripasudil 0.4\% Instillation for the Reduction of Intraocular Pressure in Japanese Open-Angle Glaucoma Patients
}

\author{
Yuko Maruyama, ${ }^{1,2}$ Yoko Ikeda, ${ }^{1,3}$ Kazuhiko Mori, ${ }^{1}$ Kengo Yoshii, ${ }^{4}$ Morio Ueno, \\ Chie Sotozono, and Shigeru Kinoshita ${ }^{5}$
}

\begin{abstract}
Purpose: Rho-associated kinase-inhibitor ripasudil 0.4\% eye drops are reportedly effective for the reduction of intraocular pressure (IOP) in glaucoma patients. However, the previous studies investigated the efficacy of IOP reduction for only about 1 year. Here, we evaluated the safety and efficacy of long-term ripasudil instillation in Japanese open-angle glaucoma (OAG) patients.

Methods: This study involved 312 eyes of 312 Japanese OAG patients newly initiated with ripasudil treatment at Kyoto Prefectural University of Medicine and Oike-Ikeda Eye Clinic, Kyoto, Japan. In all patients, adverse events leading to discontinuation of ripasudil treatment were investigated. Of the 312 patients, 129 patients able to continue ripasudil administration for over 12-months post-treatment initiation were enrolled to investigate the long-term efficacy. IOP data at 0-, 1-, 3-, 6-, 12-, 18-, and 24-months post initiation of continuous ripasudil use were obtained, and the IOP values at each time point were then compared. The first period (from 1-6 months) and second period (from 12-24 months) IOP data were also compared based on the mixed model.

Results: IOP at each time-point post-treatment initiation was significantly reduced compared with that at pre initiation $(P<0.05)$. Differences in IOP between the first and second periods of the study were not statistically significant $(P=0.058)$. Adverse events leading to discontinuation of treatment included blepharitis $(15.7 \%)$ and conjunctival hyperemia $(9.0 \%)$.

Conclusions: We found that in Japanese OAG patients, 24-month ripasudil eye drop instillation is both safe and effective for lowering IOP and that blepharitis is the primary adverse event for discontinuation of use.
\end{abstract}

Keywords: intraocular pressure, ripasudil, open-angle glaucoma

\section{Introduction}

G LAUCOMA IS THE main cause of irreversible vision loss in adults worldwide. ${ }^{1}$ Moreover, a Japanese study revealed that the estimated prevalence of glaucoma in Japanese over 40 years of age is $5 \%$. $^{2}$ Reportedly, an increase of intraocular pressure (IOP) is the primary risk factor for the development and progression of glaucoma., ${ }^{2,3}$ Thus, the most effective treatment for glaucoma is the lowering of the increased IOP, ${ }^{4,5}$ and generally, topical antiglaucoma eye-drops are used as the primary treatment for the reduction of IOP. Many patients who are diagnosed with glaucoma are treated with antiglaucoma eye-drop monotherapy as a first step; however, if the IOP lowering effect is poor or the visual field defect progresses, other types of antiglaucoma medication are typically selected as a second step. ${ }^{6}$ Recently, many new antiglaucoma eye-drop medications have been developed and approved for use in Japan, including omidenepag isopropyl (a selective EP2 agonist), ripasudil hydrochloride hydrate [a rho-associated protein kinase (ROCK) inhibitor], and brimonidine tartrate (an alpha-2 adrenergic agonist), thus providing clinicians with a wider option of eye drop medications that can be selected for treatment. ${ }^{7-10}$ However, a number of antiglaucoma eye drops, such as prostaglandin analogs, beta-blockers, carbonic anhydrase inhibitors, and alpha-2 adrenergic agonists, mainly affect

Departments of ${ }^{1}$ Ophthalmology, ${ }^{4}$ Mathematics and Statistics in Medical Sciences, and ${ }^{5}$ Frontier Medical Science and Technology for Ophthalmology, Kyoto Prefectural University of Medicine, Kyoto, Japan.

${ }^{2}$ Department of Ophthalmology, Kyoto First Red Cross Hospital, Kyoto, Japan.

${ }^{3}$ Department of Ophthalmology, Oike-Ganka Ikeda Clinic, Kyoto, Japan. 
the uveoscleral pathway or aqueous humor $(\mathrm{AH})$ production and do not mainly affect the conventional pathway. ${ }^{11}$

Ripasudil (ie, Glanatec ${ }^{\circledR}$ Ophthalmic Solution $0.4 \%$; Kowa Co., Ltd., Nagoya, Japan) was approved in Japan in September 2014 for the treatment of glaucoma and ocular hypertension. ${ }^{8}$ ROCK inhibitor eye drops, a new class of antiglaucoma medications, have been shown to lower IOP by modulating the cytoskeleton and focal adhesions in trabecular meshwork (TM) cells. It has been reported that the actin cytoskeleton plays an important role in the regulation of $\mathrm{AH}$ outflow in the TM outflow pathway, ${ }^{11,12}$ and that ROCK inhibitors decrease resistance in the TM outflow pathway and reduce IOP.

Previous studies have reported that ripasudil eye-drop instillation is effective for lowering the elevated IOP in glaucoma patients ${ }^{13-15}$; however, in those studies, the efficacy of IOP reduction was investigated for only about 1 year. ${ }^{16}$ Hence, the purpose of this study was to evaluate the safety and efficacy of long-term ripasudil $0.4 \%$ eye-drop instillation for the reduction of IOP in Japanese open-angle glaucoma (OAG) patients.

\section{Methods}

The study protocols were approved by the Institutional Review Board of Kyoto Prefectural University of Medicine, Kyoto, Japan, and all experimental procedures were conducted in accordance with the tenets set forth in the Declaration of Helsinki.

This retrospective study involved 312 eyes of 312 glaucoma patients who consulted with glaucoma specialists at the Glaucoma Service of the Department of Ophthalmology, Kyoto Prefectural University of Medicine and the OikeIkeda Eye Clinic, Kyoto, Japan, who were newly initiated with ripasudil $0.4 \%$ eye drop treatment from December 2014 to August 2018. Informed consent was obtained from all subjects before their involvement in the study.

In all patients, the factors leading to discontinuation of ripasudil eye-drop use, including adverse events, were investigated. If there were numerous factors leading to the discontinuation of ripasudil use or reasons for dropout from the long-term analysis, all factors and reasons were counted. Moreover, the elapsed period of ripasudil use at the time of ripasudil discontinuation according to each factor was separately investigated.

Of the 312 OAG patients, 129 eyes of 129 patients in whom IOP under additional ripasudil use could be observed for over 12-months post initiation of treatment with no addition of other antiglaucoma medications were enrolled to investigate the long-term efficacy of IOP reduction. IOP data at baseline (ie, pre initiation of treatment; 0 months) and at 1-, 3-, 6-, 12-, 18-, and 24-months post initiation of continuous ripasudil use was obtained, and the IOP values at each time-point were then compared. We also investigated whether or not IOP reduction (ie, that from 0- to 12-months post treatment initiation) was influenced by the number of pre treatment antiglaucoma medications used by dividing those numbers into 4 groups (ie, groups 1, 2, 3, and 4, respectively) to compare the associated IOP reduction at the 12-month time point using the Kruskal-Wallis test.

To investigate whether or not there were any additional IOP-lowering effects of ripasudil after long-term topical administration, the IOP data was also divided into 2 groups, that is, (1) changes in IOP in the first period (from 1 to 6 months post-treatment initiation) and (2) changes in the IOP in the second period (from 12 to 24 months post-treatment initiation), and then calculated as the difference between the 2 periods based on the mixed model. We included as fixed effects the 2 periods (first or second period) and the type of glaucoma [ie, normal-tension glaucoma (NTG) or primary OAG (POAG)]. Time was coded as months after the 1- and 12month time point. We included the patient as a random effect.

In the patients who underwent topical ripasudil $0.4 \%$ eye drop instillation in only 1 eye, the IOP data of that eye were used. In patients who underwent topical ripasudil $0.4 \%$ eye drop instillation in both eyes, only the right-eye data was used. Statistical analysis was performed using the paired $t$-test, the mixed model, and a $P$ value of $<0.05$ was considered statistically significant. All statistical analyses were performed using the R version 3.4.3 (R Foundation for Statistical Computing, Vienna, Austria) software with the lme4 package and the lmerTest package, and all statistical data shown in this study is presented as mean \pm standard deviation.

\section{Results}

\section{Patient characteristics}

This study involved 312 eyes (209 right eyes and 103 left eyes) of 312 glaucoma patients (151 males and 161 females; mean age: $66.7 \pm 12.6$ years). The mean observational period was $11.2 \pm 8.8$ months, and the mean number of antiglaucoma eye-drops used before the initiation of ripasudil instillation was 2.6 \pm 1.3 . Of the 312 patients, 169 were NTG patients and 143 were POAG patients (Table 1).

As for the long-term efficacy of IOP reduction, 129 eyes (85 right eyes and 44 left eyes) of 129 glaucoma patients (69 males and 60 females; mean age: $65.5 \pm 13.7$ years) were enrolled. The mean observational period was $18.3 \pm 7.6$ months and the mean number of antiglaucoma eye-drops used before the initiation of ripasudil instillation was $2.8 \pm 1.2$. Of those 129 patients, 72 were NTG patients and 57 were POAG patients (Table 1).

Table 1. Demographic Data of the Glaucoma Patients

\begin{tabular}{lcc}
\hline & $\begin{array}{c}\text { All patients } \\
\text { (312 OAG } \\
\text { patients) }\end{array}$ & $\begin{array}{c}\text { Long-term patients } \\
(129 \text { OAG patients })\end{array}$ \\
\hline $\begin{array}{l}\text { Mean patient age } \\
\text { (years) }\end{array}$ & $66.7 \pm 12.6$ & $65.5 \pm 13.7$ \\
$\begin{array}{l}\text { Gender }(n) \\
\text { Male:female }\end{array}$ & $151: 161$ & \\
$\begin{array}{l}\text { Eye used for analysis }(n) \\
\text { Right:left }\end{array}$ & $209: 103$ & $69: 60$ \\
$\begin{array}{l}\text { Glaucoma type }(n) \\
\text { POAG:NTG }\end{array}$ & $143: 169$ & $85: 44$ \\
$\begin{array}{l}\text { Mean observation } \\
\text { period (months) }\end{array}$ & $11.2 \pm 8.8$ & $57: 72$ \\
$\begin{array}{l}\text { Mean number of } \\
\text { antiglaucoma } \\
\text { eye-drops }\end{array}$ & $2.6 \pm 1.3$ & $18.3 \pm 7.6$ \\
\hline
\end{tabular}

The mean patient age, mean observational period, and mean number of antiglaucoma eye drops data are presented as mean \pm SD.

NTG, normal-tension glaucoma; OAG, open-angle glaucoma; POAG, primary OAG; SD, standard deviation. 
IOP (mmHg)

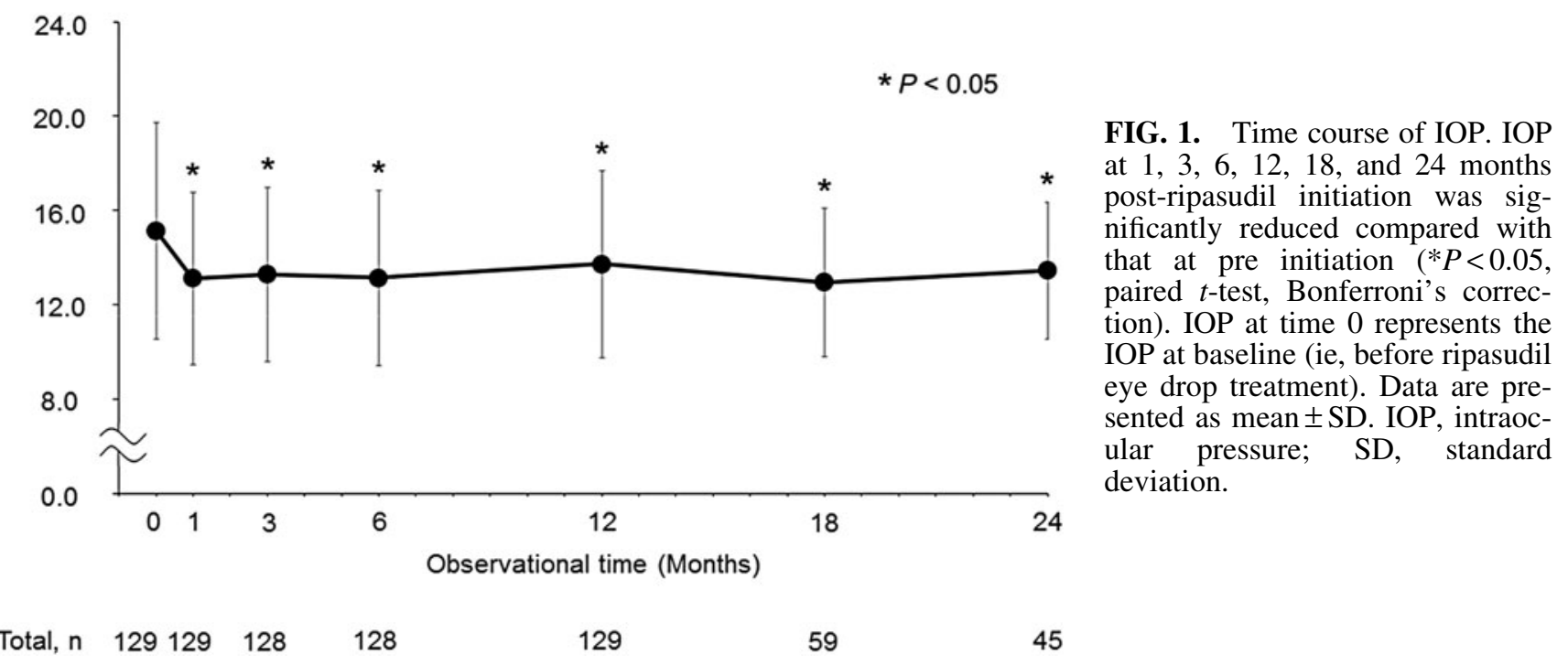

\section{Time course of IOP}

The mean IOP value at pre initiation of ripasudil was $15.1 \pm 4.6 \mathrm{mmHg}$, and at 1-, 3-, 6-, 12-, 18-, and 24-months post initiation as $13.0 \pm 3.6,13.3 \pm 3.7,13.1 \pm 3.7,13.6 \pm 4.0$, $12.8 \pm 3.2$, and $13.3 \pm 3.0 \mathrm{mmHg}$, respectively. IOP at $1-, 3-$, 6-, 12-, 18-, and 24-months post-ripasudil initiation was significantly reduced compared with that at pre initiation $(P<0.05$, paired $t$-test, Bonferroni's correction) (Fig. 1).

\section{Comparison of IOP reduction with the number of pre treatment antiglaucoma medications used}

In the patients enrolled in this study, many antiglaucoma medications were used before the initiation of treatment with ripasudil (Supplementary Table S1), and the "fixed combination" eye-drops were counted as 2 antiglaucoma medications. The IOP reduction value at the 12-month time-point with regard to $1,2,3$, and 4 pre treatment antiglaucoma medications used was $1 \mathrm{mmHg}(1,3), 1.5 \mathrm{mmHg}(-1,3), 2 \mathrm{mmHg}(0,4)$, and $1 \mathrm{mmHg}(-1,1)$, respectively [data presented as median (25th percentile, 75 th percentile)]. IOP reduction was not significantly different with the numbers of pre treatment antiglaucoma medications used $(P=0.061)$ (Fig. 2).

\section{Changes in IOP}

Changes in IOP were stratified according to the baseline IOP level. The differences in IOP between the first and the second periods of the study were not statistically significant in all patients $(P=0.058)$ (Fig. 3$)$.

\section{The main factors of the discontinuation of ripasudil use, including adverse events}

Blepharitis was the primary adverse event leading to the discontinuation of ripasudil eye-drop use (49 cases, 15.7\%). Conjunctival hyperemia was the secondary adverse event, and allergic conjunctivitis was the third most important adverse event leading to the discontinuation of ripasudil eye-drop use. In some patients, the adverse events leading to the discontinuation of ripasudil use occurred at more than 2 years after the initiation of ripasudil eye-drop instillation. As is shown in Table 2, many patients discontinued the ripasudil treatment during the study period due to a need to undergo surgery to reduce IOP or stop the progression of glaucoma (Table 2).

\section{Discussion}

In a phase- 2 randomized clinical study, Tanihara et al. reported the efficacy and safety of ripasudil eye drop instillation in POAG and ocular hypertension patients. ${ }^{13}$ Since ripasudil was officially approved for use in Japan, some

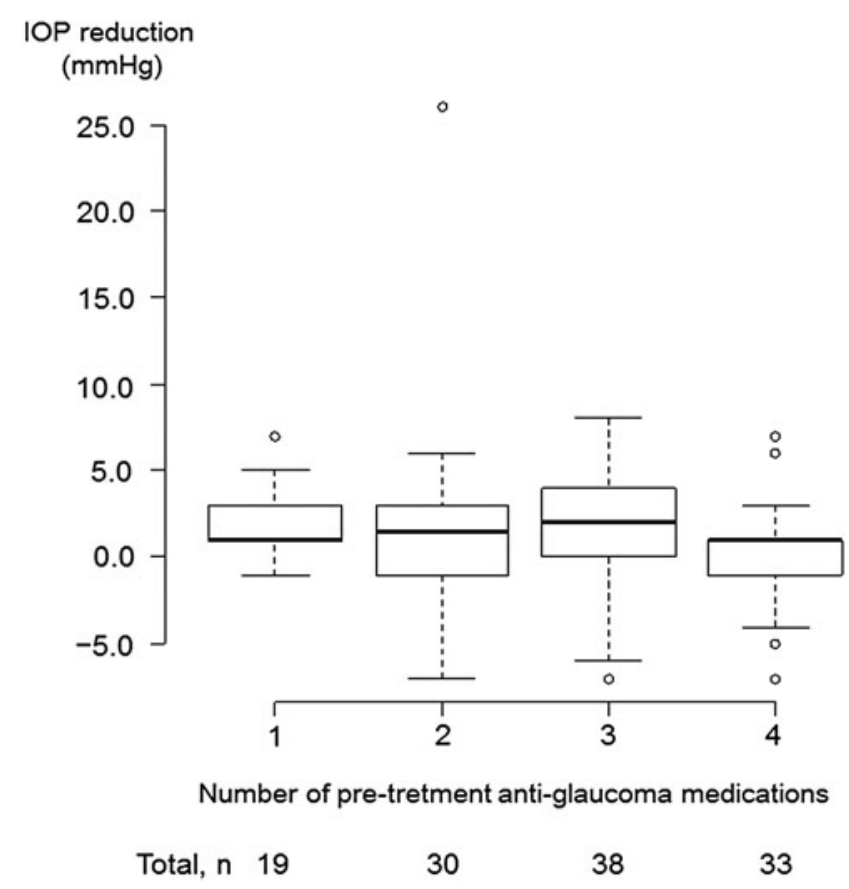

FIG. 2. Comparison of IOP reduction with the number of pre treatment antiglaucoma medications used. IOP reduction was not significantly different with the numbers of pretreatment antiglaucoma medications used $(P=0.061)$. Data are presented as median (25th percentile, 75 th percentile). 
FIG. 3. Changes in IOP. The differences in IOP between the first period (1-6 months) and the second period (after 12 months) of the study were not statistically significant $(P=0.058)$. IOP at time 0 represents the IOP at baseline (ie, before ripasudil eye-drop treatment). Data are presented as mean \pm SD

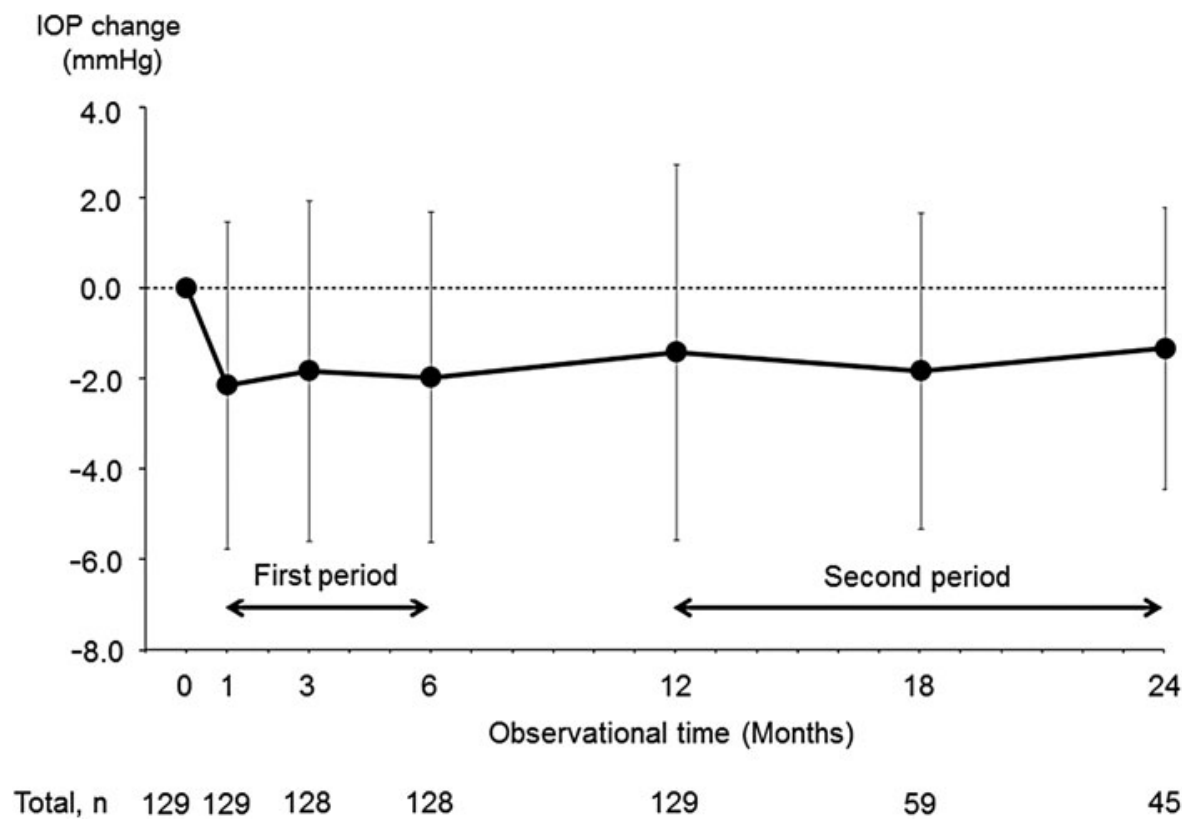

reports have shown that ripasudil eye-drop instillation is effective in glaucoma and ocular hypertension patients ${ }^{14-17}$; however, one of those studies investigated the efficacy of IOP reduction for only about 1 year. ${ }^{16}$ In this study, we investigated IOP change for a 24 -month follow-up period. IOP at 1-, 3-, 6-, 12-, 18-, and 24-months post-ripasudil initiation was reduced $2-3 \mathrm{mmHg}$ compared with that at pre initiation, thus showing that ripasudil eye drops were effective for long-term IOP reduction. Moreover, our findings showed that IOP reduction was not influenced by the numbers of pre treatment antiglaucoma medications used, as ripasudil eye drops were also found to be effective even when multiple antiglaucoma eye drops were used pre treatment. However, patients in whom IOP could not be controlled and required surgery during the time-course were excluded, thus biasing the study results. Therefore, further investigations involving a higher number of patients are needed.

It has been reported that long-term treatment with ripasudil had an additional IOP-lowering effect. ${ }^{17}$ Thus, we also compared the IOP change in 2 groups (the first period group and the second period group) to elucidate whether or not any

Table 2. All Factors for Discontinuation AND Dropout of LONG-Term Ripasudil Use ANALYSIS, INCLUDING AdVERSE EVEnts

\begin{tabular}{lcr}
\hline Factors & $\begin{array}{c}\text { Cases } \\
(\%)\end{array}$ & \multicolumn{1}{c}{$\begin{array}{c}\text { Period of } \\
\text { use (months) } \\
\text { (mean } \pm S D)\end{array}$} \\
\hline $\begin{array}{l}\text { Blepharitis } \\
\text { Undergoing surgery }\end{array}$ & $49(15.7)$ & $0-31(10.4 \pm 7.3)$ \\
Conjunctival hyperemia & $28(12.8)$ & $1-16(6.8 \pm 4.6)$ \\
$\begin{array}{l}\text { Other antiglaucoma } \\
\quad \text { medications added }\end{array}$ & $27(8.7)$ & $0.5-24(8.6 \pm 5.3)$ \\
Allergic conjunctivitis & $17(5.4)$ & $1-24(7.4 \pm 6.3)$ \\
No hospitalization & $13(4.2)$ & $0-21(9.2 \pm 7.0)$ \\
Others & $9(2.9)$ & $0-20(5.9 \pm 3.3)$ \\
\hline
\end{tabular}

The numbers listed in the cases (\%) column represents the number of patients with each specific listed factor for the discontinuation of ripasudil use and subsequent dropout from the study. additional IOP-lowering effects of ripasudil occur after long-term topical administration. The differences in IOP reduction between the first and second periods of the 24month study were found to not be statistically significant. After 12 months, some patients discontinued ripasudil eyedrop use for a variety of reasons, thus gradually reducing the total number of patients for analysis over time and possibly affecting the results. Moreover, in that previous report, the additional IOP-lowering effect was observed in ripasudil monotherapy especially in eyes with a high $\mathrm{IOP}^{17}$; however, we initiated ripasudil in patients after many other pre treatment antiglaucoma eye-drops had been used, so the IOP at pre treatment with ripasudil was not so high and could have affected our results.

In this study, we also investigated the factors related to discontinuation of ripasudil use, including adverse events. Blepharitis was the primary adverse event leading to the discontinuation of ripasudil eye drop use. In 1 patient, the discontinuation of ripasudil due to blepharitis occurred at 32months post initiation of ripasudil eye-drop use, thus illustrating that care must be taken about adverse events, not only soon after ripasudil initiation but also throughout the treatment period. Although the attached document supplied by the manufacturer of ripasudil eye drops states that blepharitis occurs in approximately $10 \%$ of the users, approximately $16 \%$ of the cases in this study discontinued use due to blepharitis. Our patients underwent long-term observation and had used multiple antiglaucoma eye-drops pre treatment, so that may explain the comparative percentage increase in blepharitis. Saito et al. also reported that the most frequently observed side effect was blepharitis, and that the 24-month discontinuation rate due to blepharitis was $34.6 \%$ (ie, a higher percentage rate than the attached manufacturer's document), similar to our results. ${ }^{18}$

The manufacturer's document on ripasudil eye-drop use also states that conjunctival hyperemia is observed in $69 \%$ of the users. However, in this study, only $9.0 \%$ of the patients discontinued ripasudil use due to conjunctival hyperemia. Saito et al. also reported that the discontinuation rate due to prolonged hyperemia was $7.8 \%,{ }^{18}$ thus illustrating, along 
with our findings, that conjunctival hyperemia is not a factor for discontinuation in many patients.

It should be noted that this study did include some limitations. First, many patients discontinued ripasudil use during the study's long-term follow-up period due to numerous reasons, such as the occurrence of blepharitis, conjunctival hyperemia, or allergic conjunctivitis, or the need to undergo surgery, a need for additional other antiglaucoma eye-drop medications, no hospitalization required, or other reasons. Thus, there may have been some selection bias in regard to the samples. Second, we also investigated the adverse effects; however, we chose adverse events that led to the discontinuation of ripasudil eye drop use, so mild-level adverse events might not have been included in the results. Finally, it should also be noted that since all of the subjects involved in this study were ethnic Japanese, the results may not be applicable to other racial groups, as we had many NTG patients.

In conclusion, the findings in this study show that 24month ripasudil $0.4 \%$ eye drop instillation is both safe and effective for IOP reduction in Japanese OAG patients, and that blepharitis is the primary adverse event leading to the discontinuation of use. However, due to the limitations in this study, further investigations are needed to better clarify the safety and efficacy of long-term ripasudil instillation for the reduction of IOP.

\section{Acknowledgments}

The authors thank Mr. John Bush for reviewing this article.

\section{Author Disclosure Statement}

No competing financial interests exist.

\section{Funding Information}

S.K. reports financial support from Kowa Pharmaceutical Co.

\section{Supplementary Material}

Supplementary Table S1

\section{References}

1. Prum, B.E., Jr., Lim, M.C., Mansberger, S.L., Stein, J.D., Moroi, S.E., Gedde, S.J., Herndon, L.W., Jr., Rosenberg, L.F., and Williams, R.D. Primary open-angle glaucoma suspect preferred practice pattern((R)) guidelines. Ophthalmology 123:P112-151, 2016.

2. Suzuki, Y., Yamamoto, T., Araie, M., Iwase, A., Tomidokoro, A., Abe, H., Shirato, S., Kuwayama, Y., Mishima, H.K., Shimizu, H., Tomita, G., Inoue, Y., and Kitazawa, Y. [Tajimi Study review]. Nippon Ganka Gakkai zasshi. 112:1039-1058, 2008.

3. Coleman, A.L., and Miglior, S. Risk factors for glaucoma onset and progression. Surv. Ophthalmol. 53:S3-10, 2008.

4. Kass, M.A., Heuer, D.K., Higginbotham, E.J., Johnson, C.A., Keltner, J.L., Miller, J.P., Parrish, R.K., 2nd, Wilson, M.R., and Gordon, M.O. The ocular hypertension treatment study: a randomized trial determines that topical ocular hypotensive medication delays or prevents the onset of primary open-angle glaucoma. Arch Ophthalmol. 120:701713; discussion 829-730, 2002.

5. Heijl, A., Leske, M.C., Bengtsson, B., and Hussein, M. Measuring visual field progression in the Early Manifest Glaucoma Trial. Acta Ophthalmol. Scand. 81:286-293, 2003.
6. [The Japan Glaucoma Society Guidelines for Glaucoma (3rd Edition)]. Nippon Ganka Gakkai zasshi. 116:3-46, 2012.

7. Sakamoto, M., Kitamura, K., and Kashiwagi, K. Changes in glaucoma medication during the past eight years and future directions in Japan based on an insurance medical claim database. J. Ophthalmol. 2017:7642049, 2017.

8. Garnock-Jones, K.P. Ripasudil: first global approval. Drugs 74:2211-2215, 2014.

9. Duggan, S. Omidenepag isopropyl ophthalmic solution 0.002\%: first global approval. Drugs 78:1925-1929, 2018.

10. Kaneko, E., Wada, T., Minagawa, Y., and Inoue, Y. [Pharmacological profile and clinical efficacy of brimonidine tartrate (AIPHAGAN((R)) ophthalmic solution 0.1\%)]. Nihon yakurigaku zasshi. Folia pharmacologica Japanica. 140: 177-182, 2012.

11. Honjo, M., Tanihara, H., Inatani, M., Kido, N., Sawamura, T., Yue, B.Y., Narumiya, S., and Honda, Y. Effects of rhoassociated protein kinase inhibitor Y-27632 on intraocular pressure and outflow facility. Invest. Ophthalmol. Vis. Sci. 42:137-144, 2001.

12. Inoue, T., and Tanihara, H. Rho-associated kinase inhibitors: a novel glaucoma therapy. Prog. Retin. Eye Res. 37:1$12,2013$.

13. Tanihara, H., Inoue, T., Yamamoto, T., Kuwayama, Y., Abe, H., and Araie, M. Phase 2 randomized clinical study of a Rho kinase inhibitor, K-115, in primary open-angle glaucoma and ocular hypertension. Am. J. Ophthalmol. 156:731736, 2013.

14. Tanihara, H., Inoue, T., Yamamoto, T., Kuwayama, Y., Abe, H., Suganami, H., and Araie, M. Intra-ocular pressurelowering effects of a Rho kinase inhibitor, ripasudil (K115 ), over 24 hours in primary open-angle glaucoma and ocular hypertension: a randomized, open-label, crossover study. Acta Ophthalmol. 93:e254-260, 2015.

15. Inoue, K., Okayama, R., Shiokawa, M., Ishida, K., and Tomita, G. Efficacy and safety of adding ripasudil to existing treatment regimens for reducing intraocular pressure. Int. Ophthalmol. 38:93-98, 2018.

16. Tanihara, H., Inoue, T., Yamamoto, T., Kuwayama, Y., Abe, H., Fukushima, A., Suganami, H., and Araie, M. Oneyear clinical evaluation of $0.4 \%$ ripasudil $(\mathrm{K}-115)$ in patients with open-angle glaucoma and ocular hypertension. Acta Ophthalmol. 94:e26-34, 2016.

17. Honjo, M., and Tanihara, H. Impact of the clinical use of ROCK inhibitor on the pathogenesis and treatment of glaucoma. Jpn. J. Ophthalmol. 62:109-126, 2018.

18. Saito, H., Kagami, S., Mishima, K., Mataki, N., Fukushima, A., and Araie, M. Long-term side effects including blepharitis leading to discontinuation of ripasudil. J. Glaucoma. 28:289-293, 2019.

Received: October 11, 2019 Accepted: January 22, 2020

Address correspondence to: Dr. Yoko Ikeda Department of Ophthalmology Kyoto Prefectural University of Medicine 465 Kajii-cho, Hirokoji-agaru Kawaramachi-dori, Kamigyo-ku Kyoto 602-0841 Japan

E-mail: yikeda@koto.kpu-m.ac.jp 